\title{
Adsorption of Basic Dye, Methylene Blue by a Novel Activated Carbon Prepared from Typha Angustata (L.)
}

\author{
M. SANTHI ${ }^{*}$ and P. E. KUMAR \\ P.G. and Research Department of Chemistry, \\ Erode Arts and Science College (Autonomous), Erode-9, Tamilnadu, India \\ santhisendil@gmail.com
}

Received 19 January 2015 / Accepted 13 February 2015

\begin{abstract}
This paper presents the feasibility of removal of basic dye methylene blue from aqueous solutions by using a low cost $\mathrm{AC}-\mathrm{MnO}_{2}-\mathrm{NC}$. Batch adsorption experiments were carried out as a function of $\mathrm{pH}$, contact time, initial concentration of the adsorbate, adsorbent dosage and temperature. Langmuir, Freundlich and Tempkin isotherms were also studied. Pseudo first order, Pseudo second order, intra-particle diffusion model and Elovich kinetic models were studied. Thermodynamic parameters such as $\Delta \mathrm{H}^{\circ}, \Delta \mathrm{S}^{\circ}$ and $\Delta \mathrm{G}^{\circ}$ were also calculated. Adsorbent used in this study were characterized by FT-IR, XRD and SEM analysis.
\end{abstract}

Keywords: Methylene blue, $\mathrm{AC}-\mathrm{MnO}_{2}-\mathrm{NC}$, Adsorption isotherm, Kinetics

\section{Introduction}

During the last few decades the mobility and distribution of dyes in water have been studied extensively due to their toxic effects to humans, animals, plants and the aquatic organisms. Many of the industries, such as dyestuffs, textile, paper, leather, foodstuffs, cosmetics, rubber and plastics are using enormous quantity of synthetic dyes in order to give colour for their products and consume substantial volumes of water. As a result, they generate a considerable amount of coloured waste water. Textile and dyeing industry are among important sources for the continuous pollution of the aquatic environment. Because they produce approximately $5 \%$ of them end up in effluents. The textile and dyeing industries effluents are discarded into rivers, ponds and lakes; they affect the biological life various organisms ${ }^{1-3}$. Dye-containing effluents are undesirable wastewaters because they contain high levels of chemicals, suspended solids, and toxic compounds ${ }^{4,5}$. Colour causing compounds can react with metal ions to form substances which are very toxic to aquatic flora and fauna and cause many water borne diseases ${ }^{6-8}$.

Due to the chemical structure of dye, they are act as a resistant to many chemicals, oxidizing agents and heat and are biologically non-degradable. So it is difficult to decolorize the effluents, once released into the aquatic environment. Many of the methods are available for the removable pollutants from water, the most important of which are reverse osmosis, ion exchange, precipitation and adsorption. 
Adsorption process has been found to be superior technique for treating dye effluents due to simplicity and insensitivity to toxic substance. Although the activated carbon ${ }^{9,10}$ is most effective for absorption of dye, but it has some disadvantages such as (i) high adsorbent cost, (ii) problems of regeneration and difficulties of separation of powdered activated carbon from waste water for regeneration are expensive and hence increasing need for equally effective but commercially low cost sorbents. A wide variety of materials such as animal bone meal ${ }^{11}$, black tea leaves ${ }^{12}, \operatorname{cocoa}^{13}$, almond shell ${ }^{14}$, mango leaves ${ }^{15}$, saw dust ${ }^{16}$.

The objective of the present study is, to remove the basic dye methylene blue from aqueous solution by using a low cost natural absorbent $\mathrm{AC}-\mathrm{MnO}_{2}-\mathrm{NC}$. In the batch mode studies, the dynamic behaviour of the adsorption was investigated on the effect on initial Dye Concentration, temperature, adsorbent dosage and $\mathrm{pH}$. The thermodynamic parameters were also evaluated from the adsorption measurements. The Langmuir, Freundlich and Tempkin adsorption isotherms, kinetics, FT-IR, XRD and SEM were also studied. Double distilled water was used throughout the experiment.

\section{Experimental}

The Typha Angustata L. plant materials were collected from local area situated at Thindal, Erode District, and Tamilnadu. They were cut into small pieces and dried for 20 days. Finally it was taken in a steel vessel and heated in muffle furnace. The temperature was raised gradually up to $500{ }^{\circ} \mathrm{C}$ and kept it for half an hour. The carbonised material was ground well and sieved to different particle size. It was stored in a plastic container for further studies. In this study particle size of 0.15 to $0.25 \mathrm{~mm}$ was used.

Preparation of $\mathrm{AC}-\mathrm{MnO}_{2}-\mathrm{NC}$

Activated carbon $(3 \mathrm{~g})$ was allowed to swell in $15 \mathrm{~mL}$ of water-free alcohol and stirred for $2 \mathrm{~h}$ at $25{ }^{\circ} \mathrm{C}$ to get uniform suspension. At the same time, the maganese dioxide $(3 \mathrm{~g})$ was dispersed into water-free alcohol $(15 \mathrm{~mL})$. Then the diluted maganese dioxide was slowly added into the suspension of activated carbon and stirred for a further 5 hours at $25{ }^{\circ} \mathrm{C}$. To this, $5 \mathrm{~mL}$ alcohol and $0.2 \mathrm{~mL}$ of deionised water was slowly added. The stirring was continued for another $5 \mathrm{~h}$ at $25{ }^{\circ} \mathrm{C}$ and the resulting suspension was kept overnight in a vacuum oven for $6 \mathrm{~h}$ at $80^{\circ} \mathrm{C}$.

\section{Preparation of sorbate}

Methylene blue $\left(\mathrm{C}_{16} \mathrm{H}_{18} \mathrm{Cl} \mathrm{N} \mathrm{S}\right)$, the sorbate used in the present study, is a monovalent cationic dye. It is classified in dye classification as C.I. Basic blue 9, C.I. Solvent blue 8 and C.I. 52015. It has a molecular weight of 373.90 and wavelength $\left(\lambda_{\max }\right)$ of $661 \mathrm{~nm}$. The methylene blue (MB)(BDH85\%) was used as supplied. A stock solution of $1000 \mathrm{mg} / \mathrm{L}$ was prepared and the working solutions were prepared by diluting the stock solution with deionized water as required.

\section{Characterization of adsorbent}

Physicochemical characteristics of the adsorbent were studied as per the standard testing methods. The XRD pattern of pure activated carbon (Figure 1) and that of $\mathrm{AC}-\mathrm{MnO}_{2}-\mathrm{NC}$ (Figure 2) show characteristic peaks at $28^{\circ}$ and $30^{\circ}$ which the presence of $\mathrm{AC}-\mathrm{MnO}_{2}$ phase in the nano composite. The surface morphology of the adsorbent were visualised via Scanning Electron Microscopy (SEM) (Figure 3 and 4). The diameter of the composite range was $10 \mu \mathrm{m}$. 




Figure 1. XRD analysis of activated carbon

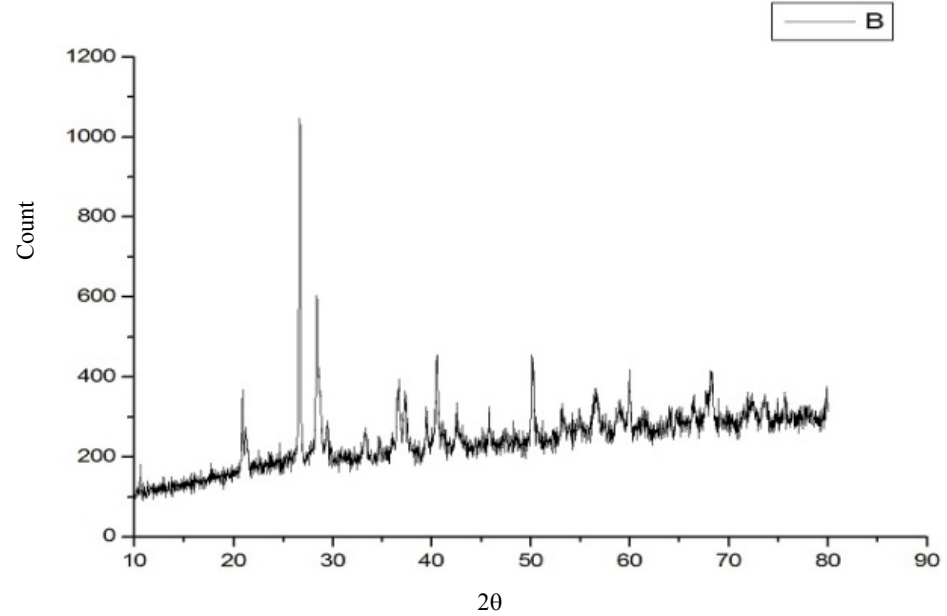

Figure 2. $\mathrm{XRD}$ analysis of $\mathrm{AC}-\mathrm{MnO}_{2}-\mathrm{NC}$

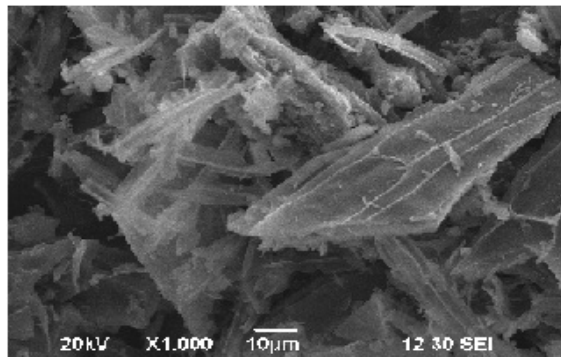

Figure 3. SEM of Activated Carbon

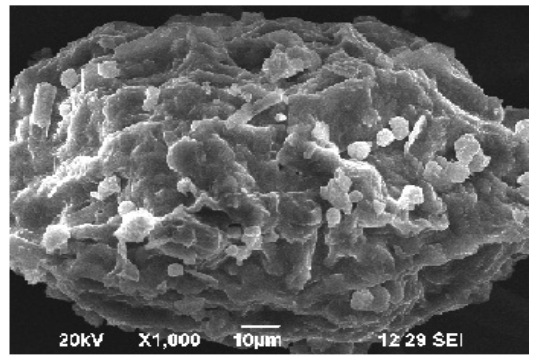

Figure 4. SEM of $\mathrm{AC}-\mathrm{MnO}_{2}-\mathrm{NC}$

\section{Experimental methods}

In each adsorption experiment, $50 \mathrm{~mL}$ of dye solution with a known concentration was added to $100 \mathrm{mg}$ of $\mathrm{AC}-\mathrm{MnO}_{2}-\mathrm{NC}$ in a $250 \mathrm{~mL}$ glass-stoppered flask at $30^{\circ} \pm 0.5^{\circ} \mathrm{C}$ and the mixture 
was stirred on a mechanical shaker at $150 \mathrm{rpm} \mathrm{min}^{-1}$. The samples were withdrawn during stirring at preset time intervals and the adsorbent was separated from the solution by centrifugation (Research centrifuge, Remi Scientific Works, Mumbai) at $4500 \mathrm{rpm} \mathrm{min}^{-1}$ for $5 \mathrm{~min}$. The absorbance of the supernatant solution was estimated to determine the residual dye concentration and was measured before and after treatment with double beam spectrophotometer (HITACHI U 2000 spectrophotometer). All experiments were carried out twice, and the concentrations given are average values. The initial dye concentration in the test solution and the adsorbent dosage were varied to investigate their effect on the adsorption kinetics. The effect of $\mathrm{pH}$ was observed by studying the adsorption of dye over the $\mathrm{pH}$ range from 3 to 13 . The $\mathrm{pH}$ of the dye solution was adjusted by using $\mathrm{NaOH}$ or $\mathrm{HCl}$ solution and a $\mathrm{pH}$ meter. The sorption studies were carried out at different temperatures $\left(30^{\circ}, 40^{\circ}, 50^{\circ}\right.$ and $60{ }^{\circ} \mathrm{C}$ ). This is used to determine the effect of temperature on the thermodynamic parameters. The amount of sorption at time $\mathrm{t}, \mathrm{q}_{\mathrm{t}}(\mathrm{mg} / \mathrm{g})$, was calculated using the following the formula:

$$
\mathrm{q}_{\mathrm{t}}=\left(\mathrm{C}_{0}-\mathrm{C}_{\mathrm{t}}\right) \mathrm{V} / \mathrm{W}
$$

Where $C_{t}\left(m^{-1}\right)$ is the liquid phase concentrations of dye at any time, $C_{0}\left(\mathrm{mg} \mathrm{L}^{-1}\right)$ is the initial concentration of the dye in solution. $\mathrm{V}$ is the volume of the solution (L) and $\mathrm{W}$ is the mass of dry adsorbent $(\mathrm{g})$. The amount of equilibrium adsorption, $\mathrm{q}_{\mathrm{e}}(\mathrm{mg} / \mathrm{g})$, was calculated using the formula;

$$
\mathrm{q}_{\mathrm{e}}=\left(\mathrm{C}_{0}-\mathrm{C}_{\mathrm{e}}\right) \mathrm{V} / \mathrm{W}
$$

Where, $\mathrm{C}_{0}$ and $\mathrm{C}_{\mathrm{e}}\left(\mathrm{mg} \mathrm{L}^{-1}\right)$ are the liquid-phase concentrations of dye initially and at equilibrium. The dye removal percentage can be calculated as follows:

$$
(\%) \text { of dye removal }=\frac{\left(\mathrm{C}_{0}-\mathrm{C}_{\mathrm{e}}\right)}{\left(\mathrm{C}_{0}\right)} \times 100
$$

Where, $\mathrm{C}_{0}$ and $\mathrm{C}_{\mathrm{e}}\left(\mathrm{mg} \mathrm{L}^{-1}\right)$ are the initial and equilibrium concentrations of the dye in solution.

\section{Results and Discussion}

\section{Effects of agitation time vs. initial dye concentration}

Effects of agitation time and initial dye concentration $(10,20,30$ and $40 \mathrm{mg} / \mathrm{L})$ on removal of MB are presented in Figure 5. The percent removal of MB increased with increase in agitation time and reached equilibrium at $210 \mathrm{~min}$. The percent dye removal at equilibrium decreased from 73.12 to 35.24 as the dye concentration was increased from 10 to $40 \mathrm{mg} / \mathrm{L}$. It is clear that the removal of dye depends on the initial concentration of the dye. The removal curves are single, smooth and continuous leading to saturation.

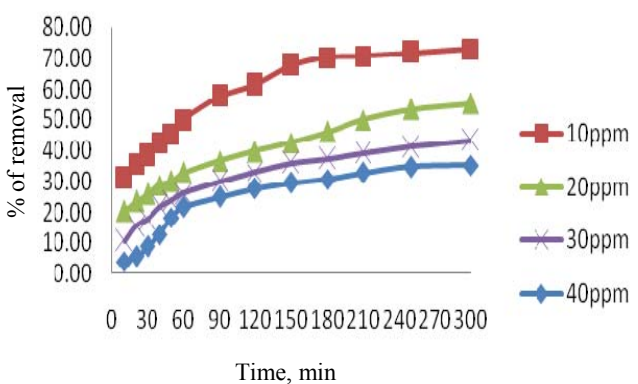

Figure 5. Effects of agitation time vs. initial dye concentration $\mathrm{MB}$ by $\mathrm{AC}-\mathrm{MnO}_{2}-\mathrm{NC}$

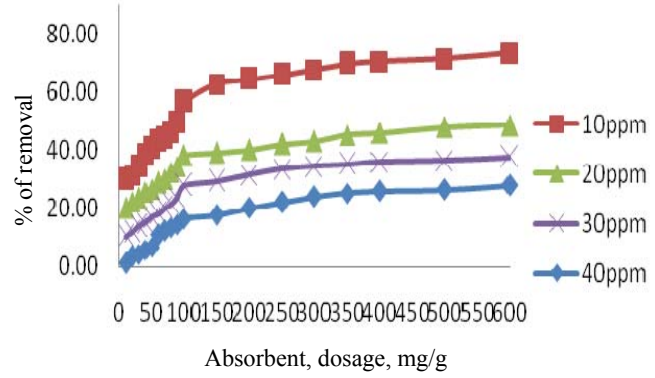

Figure 6. Effect of adsorbent dosage for $\mathrm{MB}$ by $\mathrm{AC}-\mathrm{MnO}_{2}-\mathrm{NC}$ 


\section{Effect of adsorbent dose}

The removal of $\mathrm{MB}$ by $\mathrm{AC}-\mathrm{MnO}_{2}-\mathrm{NC}$ at different adsorbent doses are presented in Figure 6 . (10 mg to $600 \mathrm{mg} / 50 \mathrm{~mL}$ ) was tested for the dye concentrations $10,20,30$ and $40 \mathrm{mg} / \mathrm{L}$. The adsorption increases with increase in adsorbent concentration; this is due to the increase in surface area and availability of more adsorption site. The percentage removal of MB is greatly increases in the range of $10-600 \mathrm{mg} / 50 \mathrm{~mL}$ after that small change occur. So the optimum adsorbent carbon doses for the experiments were carried out using $100 \mathrm{mg} / 50 \mathrm{~mL}$.

\section{Effect of $p H$}

Effect of $\mathrm{pH}$ on the removal of MB is presented in Figure 7. The solution $\mathrm{pH}$ is one of the most important factors that control the adsorption of $\mathrm{MB}$ on the adsorbent material. Therefore an increase in $\mathrm{pH}$ may cause an increase or decrease in the adsorption capacity. The adsorption capacity can be attributed to the chemical form of MB in a solution at the specific $\mathrm{pH}$ or due to different functional groups on the adsorbent surface. To examine the effect of $\mathrm{pH}$ on the percentage removal of $\mathrm{MB}$ gradually increases as the $\mathrm{pH}$ increases. The $\mathrm{pH}$ value up to 7.25 the percentage removal is up to 28.73 after that suddenly increases. At the solution $\mathrm{pH}$ the adsorbent surface negatively charged and favours uptake of cationic dyes due to increased electrostatic force of attraction. Therefore, all the experiments were carried out at the $\mathrm{pH} 7.25$. For $40 \mathrm{mg} / \mathrm{L}$ dye concentration the percent removal increased from 14.41 to 43.75 when the $\mathrm{pH}$ was increased from 2 to 14 and the percent removal remained almost the same above $\mathrm{pH} 9$.

\section{Effect of temperature}

The effect of temperature of adsorption of $\mathrm{MB}$ is presented in Figure 8. For concentration $40 \mathrm{mg} / \mathrm{L}$ adsorbent was carried out at $30^{\circ}, 40^{\circ}, 50^{\circ}$ and $60^{\circ} \mathrm{C}$. The percent removal of dye increased from 49.39 to 85.76 . This indicates that increase in adsorption with increase in temperature may be due to increase in the mobility of the large dye ions. Moreover, increasing temperature may produce a swelling effect within the internal structure of the adsorbent, penetrating the large dye molecule further.

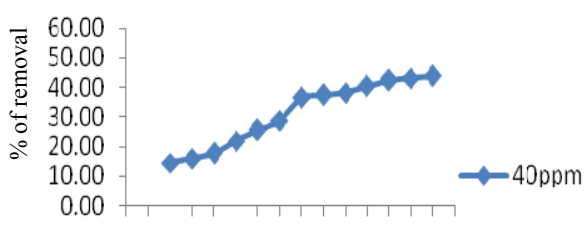

012345678910111231415

$\mathrm{pH}$

Figure 7. Effect of $\mathrm{pH}$ for $\mathrm{MB}$ by $\mathrm{AC}$ $\mathrm{MnO}_{2}-\mathrm{NC}$

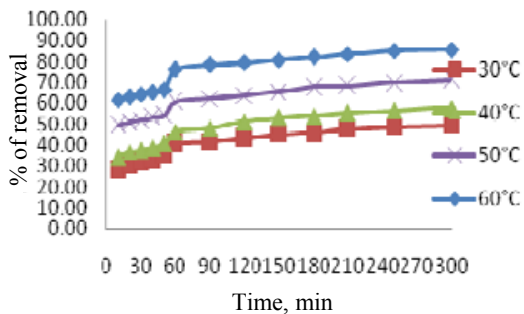

Figure 8. Effect of temperature for $\mathrm{MB}$ by $\mathrm{AC}-\mathrm{MnO}_{2}-\mathrm{NC}$

\section{Adsorption isotherms}

To quantify the adsorption capacity of the absorbent for the removal of dyes, the most commonly used isotherm, namely Freundlich and Langmuir have been adopted.

\section{Langmuir isotherm}

Langmuir isotherm model ${ }^{17}$ is based on the assumption that maximum adsorption corresponds to a saturated monolayer of solute molecules on the adsorbent surface. The linear form of the Langmuir isotherm equation can be described by 


$$
\frac{C_{e}}{q_{e}}=\frac{1}{Q_{O} K_{L}}+\frac{C_{e}}{Q_{O}}
$$

Where, $\mathrm{C}_{\mathrm{e}}$ is the concentration of dye solution $\left(\mathrm{mg} \mathrm{L}^{-1}\right)$ at equilibrium. The constant $\mathrm{Q}_{0}$ signifies the adsorption capacity $\left(\mathrm{mg} \mathrm{g}^{-1}\right)$ and $\mathrm{K}_{\mathrm{L}}(\mathrm{L} / \mathrm{mg})$ is the Langmuir isotherm constant that relates to the energy of adsorption or rate of adsorption. The linear plot of $\mathrm{C}_{\mathrm{e}} / \mathrm{q}_{\mathrm{e}} v s . \mathrm{C}_{\mathrm{e}}$ are presented in Figure 9.

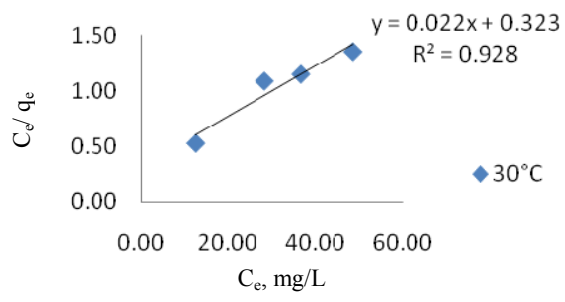

Figure 9. Plot of Langmuir adsorption isotherm

In order to find out the feasibility of the isotherm, the essential characteristics of the Langmuir isotherm can be expressed in terms dimensionless constant separation factor $\left(R_{L}\right)^{18,19}$ is given by the equation;

$$
\mathrm{R}_{\mathrm{L}}=\frac{1}{1+K_{L} C_{0}}
$$

Where $\mathrm{K}_{\mathrm{L}}$ is the Langmuir isotherm constant and $\mathrm{C}_{0}$ is the initial dye concentration $\left(\mathrm{mg} \mathrm{L}^{-1}\right)$. The parameter $\mathrm{R}_{\mathrm{L}}$ indicate the nature of the adsorption isotherm.

$$
\begin{array}{ll}
\mathrm{R}_{\mathrm{L}}>1 & \text { Unfavourable adsorption } \\
0<\mathrm{R}_{\mathrm{L}}<1 & \text { Favourable adsorption } \\
\mathrm{R}_{\mathrm{L}}=0 & \text { Irreversible adsorption } \\
\mathrm{R}_{\mathrm{L}}=1 & \text { Linear adsorption }
\end{array}
$$

The $\mathrm{R}_{\mathrm{L}}$ values between 0 to 1 which indicates favourable adsorption. Values of $\mathrm{Q}_{0}$ and $\mathrm{K}_{\mathrm{L}}$ were calculated from the slope and intercept of the linear plot and are presented in Table 1. From the Table 1 it is clear that the Langmuir isotherm constant value indicate the maximum adsorption capacity $\left(\mathrm{Q}_{0}\right)$ is $45.454 \mathrm{mg} / \mathrm{g}$. The Langmuir isotherm can also be expressed in terms of a dimensionless constant separation factor $\left(\mathrm{R}_{\mathrm{L}}\right)$. The $\mathrm{R}_{\mathrm{L}}$ values lies in between 0 to 1 indicate the adsorption is favourable for all the initial dye concentration.

\section{Freundlich isotherm}

The Freundlich isotherm ${ }^{20}$ was also applied for the adsorption of the dye. This isotherm is represented by the equation;

$$
\log \mathrm{q}_{\mathrm{e}}=\left(\frac{1}{\mathrm{n}}\right) \log \mathrm{C}_{\mathrm{e}}+\log \mathrm{k}_{\mathrm{f}}
$$

Where $\mathrm{q}_{\mathrm{e}}$ is the amount of dye adsorbed $(\mathrm{mg} / \mathrm{g})$ at equilibrium, $\mathrm{C}_{\mathrm{e}}$ is the equilibrium dye concentration in solution $\left(\mathrm{mg} \mathrm{L}^{-1}\right), \mathrm{k}_{\mathrm{f}}$ is $(\mathrm{mg} / \mathrm{g}(\mathrm{L} / \mathrm{mg}))$ measure of adsorption capacity and $1 / \mathrm{n}$ is the adsorption intensity. The magnitude of the exponent $1 / \mathrm{n}$ gives an indication of the favourability of adsorption. The value of $n>1$ represents favourable adsorption condition $^{21,22}$ or the value of $1 / \mathrm{n}$ lying in the range of 1 to 10 confirms the favourable condition for adsorption. Linear plot of $\log q_{\mathrm{e}} v s . \log \mathrm{C}_{\mathrm{e}}$ are presented in Figure 10. 
The Values of $\mathrm{k}_{\mathrm{f}}$ and $\mathrm{n}$ were calculated from the intercept and slope of the plot and are presented in Table 1. The Freundlich isotherm parameter indicates that the adsorption capacity is 10.7398 and the $\mathrm{n}$ value indicates the adsorption is favourable process.

Table 1. Langmuir, Freundlich and Tempkin constants for adsorption of $\mathrm{MB}$ by $\mathrm{AC}-\mathrm{MnO}_{2}-\mathrm{NC}$

\begin{tabular}{|c|c|c|c|c|c|c|c|c|c|c|c|}
\hline \multirow{2}{*}{ 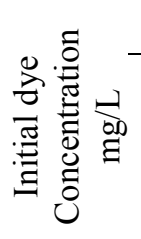 } & \multicolumn{4}{|c|}{ Langmuir } & \multicolumn{3}{|c|}{ Freundlich } & \multicolumn{4}{|c|}{ Temkin } \\
\hline & $\begin{array}{c}\mathrm{Q}_{0} \\
\mathrm{mg} / \mathrm{g}\end{array}$ & $\begin{array}{l}\mathrm{K}_{\mathrm{L}} \\
\mathrm{L} / \mathrm{g}\end{array}$ & $\mathrm{R}^{2}$ & $\mathrm{R}_{\mathrm{L}}$ & $\begin{array}{c}\mathrm{K}_{\mathrm{f}} \\
\mathrm{Mg} / \mathrm{g} / \\
\mathrm{L} / \mathrm{g}\end{array}$ & $\mathrm{n}$ & $\mathrm{R}^{2}$ & A & $\mathrm{b}$ & B & $\mathrm{R}^{2}$ \\
\hline 60 & & & & 0.1966 & & & & & & & \\
\hline $\begin{array}{c}80 \\
100\end{array}$ & 45.454 & 0.068 & 0.928 & $\begin{array}{l}0.1550 \\
0.1280\end{array}$ & 10.7398 & 3.3898 & 0.839 & 1.0917 & 290.487 & 8.529 & 0.814 \\
\hline 120 & & & & 0.1090 & & & & & & & \\
\hline
\end{tabular}

\section{Tempkin isotherm}

Tempkin isotherm contains a factor that explicitly takes into account adsorbing speciesadsorbate interactions. This isotherm assumes that: (1) The heat of adsorption of all the molecules in the layer decreases linearly with coverage due to adsorbate-adsorbate interactions and (2) Adsorption is characterized by a uniform distribution of binding energies, up to some maximum binding energy ${ }^{23}$. Tempkin isotherm is represented by the following equation:

$$
\mathrm{q}_{\mathrm{e}}=\mathrm{RT} / \mathrm{b} \ln \left(\mathrm{AC}_{\mathrm{e}}\right)
$$

equation (7) can be expressed in its linear form as:

$$
\mathrm{q}_{\mathrm{e}}=\mathrm{RT} / \mathrm{b} \ln \mathrm{A}+\mathrm{RT} / \mathrm{b} \ln \mathrm{C}_{\mathrm{e}}, \mathrm{q}_{\mathrm{e}}=\mathrm{B} \ln \mathrm{A}+\mathrm{B} \ln \mathrm{C}_{\mathrm{e}}
$$

Where $\mathrm{B}=\mathrm{RT} / \mathrm{b}$

The adsorption data can be analysed according to equation (8). A plot of $\mathrm{q}_{\mathrm{e}}$ versus $\operatorname{lnC}_{\mathrm{e}}$ enables the determination of the isotherm constants A and B and is shown in Figure 11. $\mathrm{A}$ is the equilibrium binding constant $(1 / \mathrm{mol})$ corresponding to the maximum binding energy and constant $\mathrm{B}$, is related to the heat of adsorption. This isotherm is plotted in Figure 11 for $\mathrm{MB}$ adsorption on $\mathrm{AC}-\mathrm{MnO}_{2}-\mathrm{NC}$ and values of the parameters are given in Table 1.



Figure 10. Plot of Freundlich adsorption isotherm



Figure 11. Plot of Tempkin adsorption isotherm 
Compared to the correlation coefficient $\left(\mathrm{R}^{2}\right)$ values from Table 1 shows that Langmuir isotherm is found to best.

\section{Adsorption kinetics}

The study of adsorption kinetics describes the solute uptake rate and evidently this rate controls the residence time of adsorbate uptake at the solid - solution interface. The kinetics of $\mathrm{MB}$ adsorption on the $\mathrm{AC}-\mathrm{MnO}_{2}-\mathrm{NC}$ was analysed using Pseudo first order, Pseudo second order, Elovich and Intraparticle diffusion kinetics models. The conformity between experimental data and the kinetics models was expressed by the correlation coefficients $\left(\mathrm{R}^{2}\right)$ value, the $R^{2}$ values close or equal to 1 . A relatively high $R^{2}$ value indicates that the model successfully describes the kinetics of MB dye adsorption.

\section{Pseudo first order kinetic model}

The first-order rate expression of Langergren ${ }^{24}$ equation is given as:

$$
\log \left(\mathrm{q}_{\mathrm{e}}-\mathrm{q}_{\mathrm{t}}\right)=\log \mathrm{q}_{\mathrm{e}}-\frac{k_{1}}{2.203} t
$$

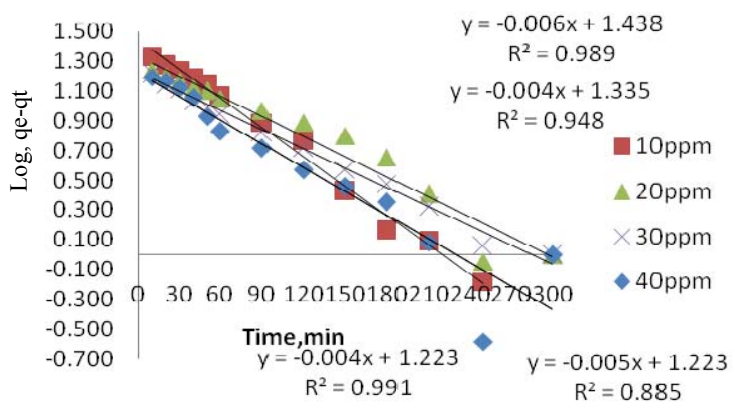

Figure 12. Pseudo first order kinetics of $\mathrm{MB}$ by $\mathrm{AC}-\mathrm{MnO}_{2}-\mathrm{NC}$

Where $\mathrm{q}_{\mathrm{e}}$ and $\mathrm{q}_{\mathrm{t}}$ are the amounts of dye adsorbed on adsorbent at equilibrium and at time $t$, respectively $(\mathrm{mg} / \mathrm{g})$ and $\mathrm{k}_{1}$ is the rate constant of first order adsorption $\left(\mathrm{min}^{-1}\right)$. The slope and intercept of plot of $\log \left(\mathrm{q}_{\mathrm{e}}-\mathrm{q}_{\mathrm{t}}\right)$ vs. $\mathrm{t}$ were used to determine $\mathrm{k}_{1}$ and $\mathrm{q}_{\mathrm{e}}$. These values are given in Figure 12 and Table 2. From the table the $\mathrm{q}_{\mathrm{e}}$ values calculated from the Pseudo first order model is less than that of the experimental value. It is does not fit for pseudo first order kinetics.

Table 2. Pseudo First order Kinetic Parameters for the adsorption of $\mathrm{MB}$ by $\mathrm{AC}-\mathrm{MnO}_{2}-\mathrm{NC}$ at various concentrations

\begin{tabular}{|c|c|c|c|c|}
\hline \multirow{2}{*}{$\begin{array}{c}\text { Initial } \\
\text { Concentration } \\
\text { of dye, } \mathrm{mg} / \mathrm{L}\end{array}$} & \multirow{2}{*}{$\begin{array}{c}\mathrm{q}_{\mathrm{e}} \text { expt, } \\
\mathrm{mg} / \mathrm{g}\end{array}$} & \multicolumn{3}{|c|}{ Pseudo First-order Kinetics } \\
\hline & & $\mathrm{q}_{\mathrm{e}}$ cal., $\mathrm{mg} / \mathrm{g}$ & $\mathrm{K}_{1}, \mathrm{mg} \mathrm{min}^{-1}$ & $\mathrm{R}^{2}$ \\
\hline 10 & 73.12 & 27.415 & $1.381 \times 10^{-2}$ & 0.989 \\
\hline 20 & 55.21 & 21.627 & $9.212 \times 10^{-3}$ & 0.948 \\
\hline 30 & 43.46 & 16.710 & $9.212 \times 10^{-3}$ & 0.991 \\
\hline 40 & 35.24 & 16.710 & $1.151 \times 10^{-2}$ & 0.885 \\
\hline
\end{tabular}

\section{Pseudo second order kinetic model}

The second-order kinetic rate equation ${ }^{25}$ is given as: 


$$
\frac{t}{q_{t}}=\frac{1}{k_{2} q_{e}{ }^{2}}+\frac{t}{q_{e}} \mathrm{t}
$$

Where $\mathrm{k}_{2}$ is the rate constant of Pseudo-second order adsorption $\left(\mathrm{gm} \mathrm{g}^{-1} \mathrm{~min}^{-1}\right)$ and $\mathrm{q}_{\mathrm{e}}$ is the maximum adsorption capacity $\left(\mathrm{mg} \mathrm{g}^{-1}\right)$. The plot of $\mathrm{t} / \mathrm{q}_{\mathrm{t}} v s$. $\mathrm{t}$ should give a linear relationship from which $\mathrm{K}_{2}$ and $\mathrm{q}_{\mathrm{e}}$ can be determined from slope and intercept of the plot, respectively. The plot and parameter of Pseudo second order of $\mathrm{MB}$ on AC-MnO2-NC are presented in Figure 13 and Table 3.

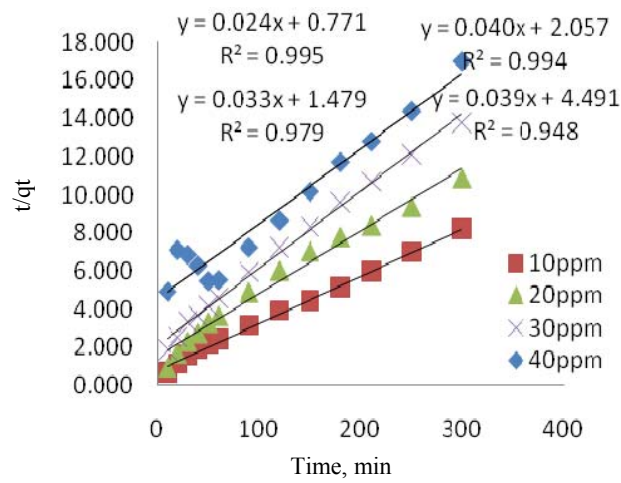

Figure13. Pseudo Second order kinetics of $\mathrm{MB}$ by $\mathrm{AC}-\mathrm{MnO}_{2}-\mathrm{NC}$

From the table $\mathrm{q}_{\mathrm{e}}$ values calculated from the Pseudo second order model are nearly equal to the experimental value and correlation coefficient $\left(\mathrm{R}^{2}\right)$ value are high compared with Pseudo first order model. So that the adsorption of MB on AC-MnO2-NC is to follow the Pseudo second order kinetic model.

Table 3. Pseudo second order Kinetic Parameters for the adsorption of MB by $\mathrm{AC}-\mathrm{MnO}_{2}$ $\mathrm{NC}$ at various concentrations

\begin{tabular}{crccc}
\hline Initial & & \multicolumn{3}{c}{ Pseudo Second-order Kinetics } \\
\cline { 3 - 5 } $\begin{array}{c}\text { Concentration } \\
\text { of dye, } \mathrm{mg} / \mathrm{L}\end{array}$ & $\begin{array}{c}\mathrm{q}_{\mathrm{e}} \text { expt,. } \\
\mathrm{mg} / \mathrm{g}\end{array}$ & $\mathrm{q}_{\mathrm{e}}$ calcd., $\mathrm{mg} / \mathrm{g}$ & $\mathrm{k}_{2}, \mathrm{mg} \mathrm{min}^{-1}$ & $\mathrm{R}^{2}$ \\
\hline 10 & 73.12 & 41.666 & $0.747 \times 10^{-3}$ & 0.995 \\
20 & 55.21 & 30.303 & $0.736 \times 10^{-3}$ & 0.979 \\
30 & 43.46 & 25.000 & $0.778 \times 10^{-3}$ & 0.994 \\
40 & 35.24 & 25.641 & $0.338 \times 10^{-4}$ & 0.948 \\
\hline
\end{tabular}

\section{Elovich kinetic model}

A simplified linearized form of Elovich kinetic equation ${ }^{26,27}$ is presented as follows:

$$
\mathrm{q}_{\mathrm{t}}=1 / \beta \ln (\alpha \beta)+1 / \beta \ln (\mathrm{t})
$$

Where $\alpha$ is the initial adsorption rate $(\mathrm{mg} / \mathrm{g} / \mathrm{min}), \beta$ is the desorption constant $(\mathrm{g} / \mathrm{mg})$ during any one experiment. A plot of $\mathrm{q}_{\mathrm{t}}$ versus $\ln (\mathrm{t})$ with a straight line, as expected, with a slope of $(1 / \beta)$ and an intercept of $(1 / \beta) \ln (\alpha \beta)$ can be calculated in Figure 14. The Elovich model parameters $\alpha, \beta$ and correlation coefficient $\mathrm{R}^{2}$ are summarized in Table 4 . From the table the initial adsorption rate $(\alpha)$, desorption constant $(\beta)$ and the correlation coefficient $\left(\mathrm{R}^{2}\right)$ are calculated. The correlation coefficient is $\left(\mathrm{R}^{2}\right)$ is less than that of Pseudo second order model. 


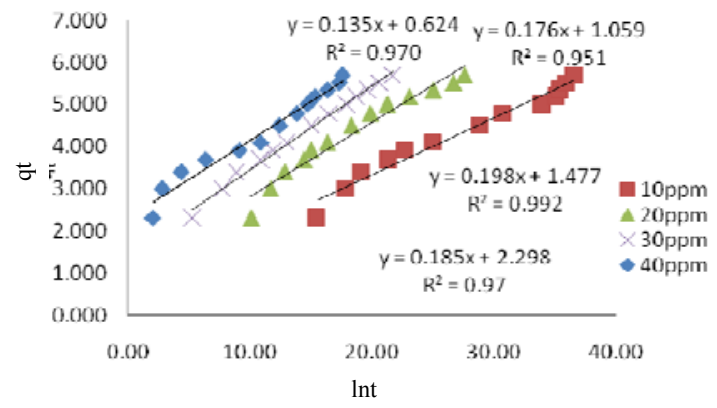

Figure 14. Elovich kinetic model of $\mathrm{MB}$ by $\mathrm{AC}-\mathrm{MnO}_{2}-\mathrm{NC}$

\section{Intraparticle diffusion model}

The intra-particle diffusion model is used here refers to the theory proposed by Weber and Morris ${ }^{28}$ based on the following equation for the rate constant:

$$
\mathrm{q}_{\mathrm{t}}=\mathrm{k}_{\mathrm{id}} \mathrm{t}^{0.5}+\mathrm{C}
$$

Where $\mathrm{K}_{\mathrm{id}}$ is the intra particle diffusion rate constant $\left(\mathrm{mg} / \mathrm{g} \mathrm{min}^{-1 / 2}\right)$ and $\mathrm{C}$ is constant. If that rate limiting step is intra particle diffusion, the graphical representation of adsorbed dye $\mathrm{q}_{\mathrm{t}}$ versus $\mathrm{t}^{0.5}$ yield straight lines passing through the origin and the slope gives the intra particle diffusion rate constant $k_{i d}$ and correlation co-efficient $\left(R^{2}\right)$ is indicated in Figure 15.

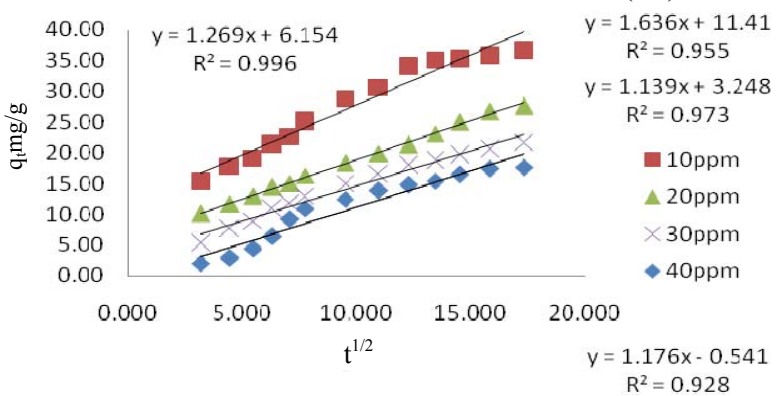

Figure 15. Intraparticle diffusion model kinetic model of $\mathrm{MB}$ by $\mathrm{AC}-\mathrm{MnO}_{2}-\mathrm{NC}$

The intra-particle parameters $\mathrm{K}_{\mathrm{id}}, \mathrm{C}$ and correlation co-efficient $\mathrm{R}^{2}$ are summarized in Table 4. From these data inter set value indicate that the line are not passing through origin, therefore some other process that may affect the adsorption. The correlation coefficient $\left(\mathrm{R}^{2}\right)$ value is high compared with Elovich model, so that the intra particle diffusion takes place along with other process that may affect the adsorption process.

Table 4. Elovich and Intraparticle diffusion Model of $\mathrm{MB}$ by $\mathrm{AC}-\mathrm{MnO}_{2}-\mathrm{NC}$

\begin{tabular}{ccccccc}
\hline Initial Dye & \multicolumn{3}{c}{ Elovich Model } & \multicolumn{3}{c}{ Intraparticle diffusion Model } \\
\cline { 2 - 7 } Concentration, mg /L & $\alpha$ & $\beta$ & $\mathrm{R}^{2}$ & $\mathrm{~K}_{\text {id }}$ & $\mathrm{C}$ & $\mathrm{R}^{2}$ \\
\hline 10 & 4.313 & 0.139 & 0.970 & 1.636 & 11.41 & 0.955 \\
20 & 4.942 & 0.185 & 0.951 & 1.269 & 6.154 & 0.996 \\
30 & 1.167 & 0.199 & 0.992 & 1.139 & 3.248 & 0.973 \\
40 & 0.561 & 0.190 & 0.970 & 1.176 & 0.541 & 0.928 \\
\hline
\end{tabular}

\section{Thermodynamic parameter}

Thermodynamic parameters like $\Delta \mathrm{H}^{\mathrm{o}}$ and $\Delta \mathrm{S}^{\mathrm{o}}$ were evaluated using Van't Hoff's equation: 


$$
\ln \mathrm{K}_{\mathrm{c}}=\Delta \mathrm{S}^{\mathrm{o}} / \mathrm{R}-\Delta \mathrm{H}^{\mathrm{o}} / \mathrm{RT}
$$

Where $\mathrm{K}_{\mathrm{c}}$ is the Langmuir equilibrium constant, $\Delta \mathrm{H}^{\mathrm{o}}$ and $\Delta \mathrm{S}^{\mathrm{o}}$, are the standard enthalpy and entropy changes of adsorption respectively and their values are calculated from the slopes and intercepts respectively of the linear plot of $\ln \mathrm{K}_{\mathrm{c}} v \mathrm{~s} .1 / \mathrm{T}$. The free energy change for the adsorption process $\Delta \mathrm{G}^{\mathrm{O}}(\mathrm{kJ} / \mathrm{mol})$ is derived in equation 14 .

$$
\Delta \mathrm{G}^{\mathrm{o}}=\Delta \mathrm{H}^{\mathrm{o}}-\mathrm{T} \Delta \mathrm{S}^{\mathrm{o}}
$$

The values of these parameters were calculated using equation 13 and 14 at various initial concentrations and are shown in Table 5.

\begin{tabular}{|c|c|c|c|c|c|}
\hline \multicolumn{4}{|c|}{$\Delta \mathrm{G}^{\mathrm{o}}, \mathrm{kJ} / \mathrm{mol}$} & $\Delta \mathrm{S}^{\mathrm{o}}, \mathrm{J} / \mathrm{mol} / \mathrm{K}$ & $\Delta \mathrm{H}^{\mathrm{o}}, \mathrm{kJ} / \mathrm{mol}$ \\
\hline $\begin{array}{c}303 \mathrm{~K} \\
-51.541\end{array}$ & $\begin{array}{c}313 \mathrm{~K} \\
-53.244\end{array}$ & $\begin{array}{c}323 \mathrm{~K} \\
-54.947\end{array}$ & $\begin{array}{c}333 \mathrm{~K} \\
-56.649\end{array}$ & 170.270 & 50.274 \\
\hline
\end{tabular}

Table 5. Thermodynamic parameters for the adsorption of $\mathrm{MB}$ by $\mathrm{AC}-\mathrm{MnO}_{2}-\mathrm{NC}$

The adsorption data indicates that $\Delta \mathrm{G}^{\mathrm{o}}$ were negative at all temperatures. The negative $\Delta \mathrm{G}^{\mathrm{o}}$ confirms the spontaneous nature of adsorption of $\mathrm{MB}$ with $\mathrm{AC}-\mathrm{MnO}_{2}-\mathrm{NC}$. The magnitude of $\Delta \mathrm{G}^{\mathrm{o}}$ suggests that adsorption is physical adsorption process. The positive value of $\Delta \mathrm{H}^{\circ}$ were further confirms the endothermic nature of adsorption process. The positive $\Delta \mathrm{S}^{\mathrm{o}}$ showed increased randomness at the solid-solution interface during the adsorption of $\mathrm{MB}$ dye on $\mathrm{AC}-\mathrm{MnO}_{2}-\mathrm{NC}$. This was also further supported by the positive values of $\Delta \mathrm{S}^{\circ}$, which suggest that the freedom of MB is not too restricted in the adsorbent, confirming a physical adsorption. The $\Delta \mathrm{G}^{\mathrm{o}}$ value increases with increase in temperature is the increase in enhancement of the adsorption capacity of adsorbent may be due to increase or enlargement of pore size and/or activation of the adsorbent surface.

\section{Desorption studies}

After activated carbon is saturated with dye molecules, different solvents could be used to regenerate the activated carbon to restore its dye adsorptive capability ${ }^{29}$. Desorption with acetic acid revealed that the regeneration of adsorbent was satisfactory, which confirms the physisorptive nature of adsorption.

\section{Conclusion}

The present study shows that AC-MnO2-NC is an effective adsorbent for the removal of $\mathrm{MB}$ from aqueous solution. Adsorption followed the Langmuir isotherms. The adsorption capacity was found to be $45.454 \mathrm{mgg}^{-1}$. The thermodynamic parameters were found to be thermodynamically favourable physical adsorption process. Evaluation of thermodynamic parameters showed the process as endothermic and spontaneous. The kinetic parameters fit for Pseudo second order model. Desorption studies reveals that satisfactory desorption taking place confirming physisorptive nature of adsorption. Complete removal of the dye can be achieved using an appropriate dosage of the adsorbent and $\mathrm{pH}$ for waste waters. The results would be useful for the fabrication and designing of waste water treatment plants for the removal of dye. Since the raw material is freely available in large quantities the treatment method, seems to be economical.

\section{References}

1. HO Y S and McKay G, Canadian J Chem Eng., 1998, 76(4), 822-827; DOI:10.1002/cjce.5450760419

2. Walker G M, Hansen L, Hanna J A and Allen S J, Water Res,. 2003, 37(9), 20812089; DOI:10.1016/S0043-1354(02)00540-7 
3. Stydini M, Dimitris I K, Verykios X E, Appl Catal B: Environ., 2004, 47(3), 189-201; DOI:10.1016/j.apcatb.2003.09.014

4. Wesemberg D, Buchon F and Agathos S N, Biotech Lett., 2003, 24(12), 989-993; DOI:10.1023/A:1015660927710

5. Valeria P, Giovanna C, Leonardo C and Valeria F M, Bioresour Technol., 2008, 99(9), 3559-3567; DOI:10.1016/j.biortech.2007.07.053

6. Karthikeyan J, Trivedi RK(ED), Pollution Management in industries, Environmental Publications, India. 1989, 150.

7. Ohea T, Watanabeb T and Wakabayashic K, A Review, Mutation Res., 2004, 567(23), 109-149; DOI:10.1016/j.mrrev.2004.08.003

8. $\quad$ Nosheen S, Nawaz H and Ur-Rehman K, Int J Agri Biology., 2000, 2(3), 232-233.

9. Lalitha P and Sangeetha S N, Oriental J Chem., 2008, 24(3), 983-988.

10. Vasu A E, E - J Chem., 2008, 5(4), 844-852; DOI:10.1155/2008/271615

11. El Haddad M, Mamouni R, Saffaj N and Lazar S, Global J Human Soc Sci Geography and Environ GeoSci., 2012, 12(10), 19-30

12. Abul Hossain M and Afiqur R M, Orbital Elec J Chem Campo Grande, 2012, 4(3), 187-201.

13. Theivarasu C and Mylsamy S, Int J Eng Sci Technol., 2010, 2(11), 6284-6292.

14. Aliabadi M, Khazaei I, Hajiabadi M and Shahrzad F, J Biodiversity Environ Sci., 2012, 2(9), 39-44.

15. Khan T A, Sharma S and Ali I, J Toxicol Environ Health Sci., 2011, 3(10), 286-297.

16. Wttek-Krowiak A, Mittek M, Pokomeda K, Szafran R G and Modelski S, Chem Process Eng., 2010, 31, 409-420.

17. Langmuir I, J Am Chem Soc., 1918, 40(9), 1361-1403; DOI:10.1021/ja02242a004

18. Ferrero F, J Hazardous Mater., 2007, 142(1-2), 144-152; DOI:10.1016/j.jhazmat.2006.07.072

19. Mckay G, Blair H S and Gardner J R, J Appl Polym Sci., 1982, 27(8), 3043-3057; DOI:10.1002/app.1982.070270827

20. Freundlich H Z, Phys Chem., 1906, 57, 384-470.

21. Treybal R E, Mass Transfer Oprerations, Second Ed., McGraw Hill, New York 1968.

22. Ho Y S and Mckay G, Chem Engg J., 1998, 70(2), 115-124; DOI:10.1016/S09230467(98)00076-1

23. Tempkin M J and Pyzhev V, Acta Physiochim URSS, 1940, 12, 217-22.

24. Langergren S. Kungliga Svenska Vetenskapsakademies Handlinger, 1898, 24, 1-39.

25. Ho V S and Mckay G, Water Res., 2000, 34(3), 735-742; DOI:10.1016/S00431354(99)00232-8

26. Chien S H, Clayton W R, Soil Sci Soc Am J., 1980, 44(2), 265-268; DOI:10.2136/sssaj1980.03615995004400020013x

27. Sparks D L, Kinetics of Reaction in Pure and Mixed Systems in Soil Physical Chemistry. CRC Press, Boca Raton, 1986.

28. Weber W J and Morris J C, J Sanitary Engg Division, 1964, 90, 79-107.

29. Bai X, Yuan F S, Zhang T, Wang J X, Wang H and Zhang W Z, J Environ Health, 2012, 29(1), 51-54. 